\title{
Formação de professores em Modelagem Matemática no contexto do Programa de Desenvolvimento Educacional do Paraná, PDE*
}

\author{
Teachers' education in Mathematical Modeling \\ in an Educational Development Program of Paraná, EDP
}

Carla Melli Tambarussi ${ }^{1}$. Tiago Emanuel Klüber ${ }^{2}$

\begin{abstract}
Resumo: Este artigo busca apresentar e discutir reflexões sobre o fenômeno formação de professores em modelagem a partir de professores egressos do PDE. Tais reflexões se constituíram na interpretação dos dados (depoimento e observação das aulas) de oito professores que participaram do Programa de Desenvolvimento Educacional (PDE) do Estado do Paraná e que utilizaram a Modelagem Matemática em seus projetos de implementação. Essas reflexões apontam para fragilidades com que as formações têm sido desenvolvidas, bem como para aspectos tidos como fundamentais na formação de professores, mas, que precisam ser questionados: "uma formação adequada exige um tempo maior"; "uma formação que envolva a prática pedagógica garante mudanças em sala de aula". Assim, diferentes reflexões se mostram significativas para que a formação de professores em Modelagem possa avançar e contribuir para a sua permanência em âmbito educacional.
\end{abstract}

Palavras-chave: Formação continuada de professores. Educação matemática. Fenomenologia. Programa de desenvolvimento educacional. Modelagem matemática.

\begin{abstract}
This article seeks to present and discuss reflections about the phenomenon teachers' education in Modeling from teachers who are former students of EDP. These reflections consisted of the interpretation of the data (interview and observation of the classes) of eight teachers who participated to the Educational Development Program (EDP) of Paraná State and used Mathematical Modeling in their implementation projects. These reflections point to weaknesses with the teachers' education, as well as aspects taken as fundamental in the teachers' education, but which need to be questioned: "adequate teacher education requires a longer time"; "The teachers' education that involves pedagogical practices ensures changes in the classroom". Thus, different reflections are significant that the teachers' education in Modeling can advance and contribute to the permanence of Modeling in the educational field.
\end{abstract}

Keywords: Continuing teachers' education. Mathematics education. Phenomenology. Educational Development Program. Mathematics modeling.

\footnotetext{
* Este trabalho é parte da dissertação de mestrado da primeira autora, orientada pelo segundo autor. Uma primeira versão, menos aprofundada, foi apresentada no VI Seminário Internacional de Pesquisa em Educação Matemática (SIPEM).

${ }^{1}$ Universidade Estadual Paulista (Unesp), Rio Claro, SP, Brasil. Orcid: <http://orcid.org/0000-0002-4359-1766>. E-mail: <carlatambarussi@hotmail.com>.

${ }^{2}$ Universidade Estadual do Oeste do Paraná (Unioeste), Centro de Ciências Exatas e Tecnológicas, Cascavel, PR, Brasil.
} 


\section{Contexto e metodologia do investigado}

A formação de professores de Matemática é um tema de pesquisa recorrente em todas as áreas que formam professores, e não é diferente na comunidade de Educadores Matemáticos. Esse tema é tão relevante que possui um Grupo de Trabalho (GT) próprio na Sociedade Brasileira de Educação Matemática (SBEM), alocado no GT07, Formação de Professores que Ensinam Matemática. Esse GT “[...] dedica-se ao estudo e à pesquisa relacionados à formação e desenvolvimento profissional de professores que lecionam Matemática em qualquer nível de ensino, em situações formais e/ou informais" (EMENTA..., 2012). O GT vem agendando encontros para discutir diferentes temáticas relacionadas à formação de professores de Matemática como: formação inicial; formação continuada; políticas públicas; processos colaborativos, entre outros. Esses aspectos podem ser observados, por exemplo, nos trabalhos de Carneiro (2015), Passos e Souza (2015), Fanizzi e Santos (2015), Giusti e Justo (2015) e Santana e Barbosa (2015), publicados nos anais do último Seminário Internacional de Pesquisa em Educação Matemática (SIPEM) $^{3}$, realizado em 2015 na cidade Pirenópolis no Estado de Goiás.

Num olhar desavisado, poderia se pensar que é possível uma formação homogênea ao professor que ensina Matemática. No entanto, ao nos determos sobre aspectos que transcendem e simultaneamente abarcam a Matemática, como por exemplo, a esfera metodológica, nos deparamos com especificidades para a formação do professor de Matemática. Em outras palavras, ensinar Matemática por meio de uma determinada metodologia, ou um modo de ensino, requer compreender a formação do professor de Matemática quando se vale dessa metodologia ou modo de ensino.

Sob esse entendimento, sem desconsiderar aspectos gerais da formação de professores de Matemática, os quais, como já mencionado vêm sendo discutidos pelos pesquisadores do GT07, dirigimo-nos à formação do professor de Matemática em Modelagem Matemática, tema que temos nos dedicado nos últimos anos (TAMBARUSSI; KLÜBER, 2014a).

$\mathrm{O}$ interesse pelo tema e a sua pertinência decorrem de vários argumentos que podem ser encontrados na literatura, dentre os quais destacamos:

1. As pesquisas sobre formação de professores em Modelagem Matemática são recentes;

2. As pesquisas abordam temas que merecem aprofundamentos, como por exemplo:

a) a Modelagem Matemática nos anos iniciais;

b) a compreensão da influência dos programas de formação na prática dos professores (BARBOSA, 2001a);

c) aspectos epistemológicos e filosóficos da Modelagem Matemática;

d) pesquisas com características de mapeamento.

Esses aspectos foram destacados em Tambarussi e Klüber (2014b) quando mapeamos os focos das dissertações e teses sobre Modelagem na perspectiva da Educação Matemática realizadas no período de 1989 a 2011, e, a partir deles, podemos afirmar que há ainda muito

\footnotetext{
${ }^{3}$ Disponível em: <http://www.sbembrasil.org.br/visipem/> Acesso em: 29 ago 2016.
} 
que se avançar na comunidade brasileira de Modelagem quando o assunto é a formação de professores nessa tendência ${ }^{4}$.

Dentre as lacunas a serem preenchidas na área, nos dedicamos, particularmente, àquela que dizia sobre: o momento posterior à participação dos professores em atividades de formação continuada ${ }^{5}$. Nesse contexto, voltamos nossa atenção para o $\mathrm{PDE}^{6}$, que além de não ter sido abordado em nenhum dos trabalhos mapeados, refere-se a uma política de formação continuada para professores concursados da rede estadual de ensino que busca proporcionar uma formação continuada que se diferencie daquilo que tem sido ofertado, como evidenciam os pressupostos assumidos na proposta do programa:

[...] a) reconhecimento dos professores como produtores de conhecimento sobre o processo ensino-aprendizagem; b) organização de um programa de formação continuada atento às reais necessidades de enfrentamento de problemas ainda presentes nas escolas de Educação Básica; c) superação do modelo de formação continuada concebido de forma homogênea e descontínua; d) organização de um programa de formação continuada integrado com as instituições de ensino superior; e) criação de condições efetivas, no interior da escola, para o debate e promoção de espaços para a construção coletiva do saber (PARANÁ, 2013, p. 2).

Esses aspectos, concernentes à região de inquérito em que nos situamos, subsidiaram a definição do tema de nossa dissertação de mestrado, sob a interrogação: O que se revela sobre a formação de professores em Modelagem Matemática, a partir de professores egressos do PDE, que abordaram a Modelagem em seus projetos de implementação? (TAMBARUSSI, 2015). Essa indagação nos conduziu, primeiramente, a efetuar uma busca no site do $\mathrm{PDE}^{7}$ de trabalhos que se diziam de Modelagem Matemática. Essa busca nos fez eleger, como sujeitos da pesquisa, oito professores egressos

\footnotetext{
${ }^{4}$ Aqui tendência não é entendida como no senso comum, ou seja, apenas um modismo que vem e passa, uma vez que a Modelagem é estudada desde a década de 1970. Tendência é entendida neste trabalho como um movimento efetivo daquilo que tem permanecido enquanto e como alguns modos de se pensar e fazer Educação Matemática em nosso país e também em outras partes do mundo (KLÜBER, 2012a).

5 "Formação continuada" é entendida aqui como uma formação complementar (ainda que não concordemos com o termo), isto é, para além da formação inicial. A ideia de formação continuada entrou em evidência, a partir da LDB de 1996 e é considerada como direito de todos os profissionais da Educação que estão em efetivo exercício e foram formados em cursos reconhecidos (BRASIL, 1996).

${ }^{6}$ O Programa de Desenvolvimento Educacional do Paraná - PDE, desde o ano de 2010 é considerado uma política de formação continuada da Rede Pública Estadual de Ensino do Paraná. É destinado aos professores concursados e que estão na classe de 8 a 11, do nível 2, da tabela de vencimentos do plano de carreira. O PDE, ao menos no nível da proposta, busca proporcionar aos professores subsídios teórico-metodológicos e o estabelecimento de diálogo entre professores do Ensino Básico e do Ensino Superior que resulte em mudanças na prática escolar da escola pública. Além disso, é um programa que proporciona a ascensão na carreira profissional do professor que ingressa nesse processo de formação (PARANÁ, 2013).

${ }^{7}$ Disponível em: <http://www.gestaoescolar.diaadia.pr.gov.br/modules/conteudo/conteudo.php?conteudo $=20>$. Acesso em: 01 set 2016.
} 
do PDE, que mencionaram ter utilizado a Modelagem Matemática em seus projetos de implementação pedagógica. Essa quantidade de professores se justifica pelo fato de trabalharem em escolas da região Oeste do Estado, contribuindo para a coleta de materiais significativos à produção dos dados da pesquisa.

No que se refere a esse item, ele se deu a partir da recolha de depoimentos e da observação da prática docente em sala de aula, em que quatro dos oito professores permitiram ser acompanhados. Esses procedimentos metodológicos vão ao encontro da atitude fenomenológica assumida frente a pesquisa, pois possibilitam "[...] a livre expressão dos participantes, que é essencial tanto para a descrição quanto para a interpretação da experiência vivida” (GIL, 2010, p. 137).

Nesse sentido, acrescentamos que a nossa interrogação se instaura no âmbito da filosofia, mais especificamente, se aproxima da postura filosófica de produção do conhecimento, uma vez que não trata de objetos da mesma forma como faz as Ciências Naturais, pois trata "[...] do modo como os objetos se dão, trata das condições de possibilidades" (STEIN, 2004, p. 23) e não de objetos em si, num sentido realista ingênuo (HESSEN, 1980). Assim, há uma infinidade de maneiras de o nosso fenômeno "Formação de Professores em Modelagem a partir de professores egressos do PDE” se mostrar. E ficamos atentos às manifestações possíveis de serem compreendidas no fluxo temporal e intencional e buscamos transcendê-las.

No que se refere à análise, contamos com o auxílio do software Atlas t.i., para organização dos materiais coletados e, após o processo de categorização, efetuamos a interpretação, de cunho fenomenológico hermenêutico. Tal atitude, não impõe a definição prévia de referenciais teóricos, ou seja, ao assumirmos a atitude fenomenológica não restringimos o fenômeno a um único modo de manifestação, mas, o consideramos sob os diversos modos de se mostrar. Isso, por sua vez, significa que "[...] não trabalhamos com categorias elencadas a partir de um quadro teórico elaborado a priori ou a partir de instrumentos de pesquisa externos a essa investigação" (BICUDO, 2000, p. 82). Portanto, as categorias emergiram do destaque de unidades de significado $^{8}$ dos depoimentos e relatórios produzidos ao longo da investigação.

Além disso, conduzir as interpretações utilizando a hermenêutica significa, segundo Bicudo (2006, p. 112) que essa interpretação irá privilegiar “[...] os significados social e historicamente atribuído às manifestações do que, uma vez foi compreendido na percepção, mas que não se materializou nas palavras". E num sentido filosófico, “[...] A hermenêutica carrega consigo a ideia de tornar explícito o implícito, de descobrir a mensagem, de torná-la compreensível, envolvendo a linguagem nesse processo" (HERMANN, 2002, p. 24).

Assim, conduzidos pela nossa interrogação, analisamos e interpretamos os dados, ou seja, aquilo que se mostrou da leitura dos depoimentos e prática de cada professor, separadamente, para, somente ao final da dissertação, apresentarmos um discurso articulando as

\footnotetext{
8 “"...] as unidades de significado, por sua vez, são recortes considerados significativos pelo pesquisador, dentre os vários pontos aos quais a descrição pode levá-lo. Para que as unidades significativas possam ser recortadas, o pesquisador lê os depoimentos à luz da sua interrogação por meio da qual pretende ver o fenômeno que é olhado de uma dentre as várias perspectivas possíveis" (GARNICA, 1999, p. 120).
} 
categorias convergentes de cada docente e aquelas que se mostraram idiossincráticas ${ }^{9}$. As categorias que emergiram dos dados dos oitos professores investigados dizem: (1) do Programa de Desenvolvimento Educacional; (2) dos cursos desenvolvidos durante o PDE; (3) do projeto de implementação pedagógica; (4) da prática pedagógica; (5) do discurso acerca da prática; (6) do momento posterior à participação no PDE; (7) de considerações sobre a Modelagem Matemática antes do PDE; (8) da Modelagem Matemática; (9) da formação de professores; (10) da modalidade Educação de Jovens e Adultos (EJA); (11) da Modelagem e os alunos; (12) do currículo e a Modelagem; (13) da disciplina de Matemática.

Essas categorias, de um modo geral e transitivamente, abordam os diferentes modos que o fenômeno Formação de Professores em Modelagem a partir de professores egressos do PDE tem de se mostrar. No contexto da dissertação, essas categorias revelam diferentes aspectos que são relevantes para a formação de professores em Modelagem Matemática. No entanto, mediante a impossibilidade de apresentar todos os resultados neste manuscrito, optamos por retomar os aspectos que se articulam, numa perspectiva meta-analítica, conforme indica Bicudo (2014). Em suma, apresentaremos uma síntese daquilo que foi registrado na dissertação.

O modo de exposição admitido aqui fará menção às categorias individuais que emergiram para cada docente e serão interpretadas e articuladas sob uma categoria mais ampla. Além disso, algumas delas remetem ou dão sentido a outra categoria, solicitando um estilo textual não linear. Buscamos, também, acrescentar as unidades de significado destacadas das transcrições dos depoimentos de oito professores (P1, P2, P3, P4, P5, P6, P7, P8) e dos diários de observações construídos em cada aula observada. As unidades, ao serem destacadas no software Atlas t.i., são organizadas a partir de códigos, por exemplo: 1:3, que indica a terceira unidade destacada do primeiro documento primário. De modo geral, estaremos nos referindo à formação de professores em Modelagem Matemática no âmbito do PDE.

\section{A formação de professores em Modelagem Matemática no âmbito do PDE}

Há vários aspectos mencionados pelos professores que sugerem a valorização do Programa de Desenvolvimento Educacional do Paraná, enquanto política de formação continuada. Dentre eles, estão a possibilidade de dedicação exclusiva de um ano para estudos, a implementação de atividades relacionadas ao projeto em desenvolvimento no PDE e a progressão no plano de carreira ${ }^{10}$.

\footnotetext{
9 “[...] fenomenologicamente, uma idiossincrasia não carrega consigo julgamento valorativo, entendido aqui como ter valor menor do que as convergências maiores. Mas seu significado é compreendido à luz de estar sozinha, não se articulando com outros significados, podendo ser destacada em termos de inovação, ou ainda, como sendo, importante apenas em um caso" (BICUDO; PAULO, 2011, p. 270).

${ }^{10} \mathrm{O}$ plano de carreira do professor da rede estadual de educação básica do Paraná objetiva o aperfeiçoamento profissional contínuo e a valorização do professor através de remuneração digna e, por consequência, a melhoria do desempenho e da qualidade dos serviços prestados à população do estado. A palavra carreira, nesse contexto, se refere ao conjunto de níveis e classes que definem a evolução funcional e remuneratória do professor, de acordo com a complexidade de atribuições e grau de responsabilidade.
} 
No entanto, analisando de modo cuidadoso a proposta do PDE (PARANÁ, 2013) e aspectos dos depoimentos dos professores, observamos, de modo geral, que o programa não tem se constituído em um lócus que possa contribuir para a mudança da prática educativa do professor na atuação em sala de aula, e, para a superação das suas dificuldades, bem como, para a compreensão e implementação de novas metodologias, novas perspectivas ou inovações educacionais. Isso se mostra, por exemplo, quando nos depoimentos de alguns professores emerge o discurso de que a formação ofertada no PDE deveria ser voltada para a sala de aula. Nesse sentido, destacamos, respectivamente, os relatos dos professores P3, P5 e P6: "[1:89] Ponto negativo foram as disciplinas que não acrescentaram nada"; "[1:52] Para a atuação em sala de aula, o professor não viu acréscimo nos cursos ofertados pelo PDE"; "[1:95] O PDE virou um curso para cumprir tabela"; "[1:34] Não ajudou na sua formação enquanto professor da Educação Básica"; "[1:35] O PDE deveria ser mais voltado às metodologias, ao trabalho com essas metodologias"; "[1:41] A formação no PDE deveria ser voltada mais para o dia a dia da sala de aula. De que forma trabalhar o conteúdo".

Essas afirmações vão ao encontro do que é apresentado na categoria "Sobre os cursos no PDE”, pois revelam como os cursos, foram conduzidos, quais eram os enfoques. Dizemos que vai ao encontro, tendo em vista que essa categoria evidenciou que muitos cursos se voltaram para aspectos do Ensino Superior, isto é, para uma Matemática, que num primeiro momento, não encontra relações com aquilo que o professor precisa desenvolver no âmbito da Educação Básica, como explicitam, por exemplo, as unidades de significado do professor P5: "[1:47] Alguns cursos ofertados se aproximavam de uma revisão para um acadêmico"; "[1:48] Os enfoques dos cursos não estavam direcionados para os professores da Educação Básica"; do professor P6: "[1:33] No PDE vi uma Matemática mais avançada, pura”; "[1:37] A parte específica foi voltada para uma Matemática mais avançada”; e, do professor P8: "[1:24] A parte da Matemática foi voltada ao Ensino Superior"; "[1:25] Alguns professores propuseram atividades voltadas ao Ensino Superior outros nem isso".

Esse aspecto mostra que os professores responsáveis por ministrarem esses cursos, envolvidos com a formação ofertada no PDE, não se preocuparam, ao menos de modo constante e sistemático, em articular: as propostas curriculares, a pesquisa em Educação Matemática e o contexto da Educação Básica, ao nível que o professor participante do PDE atua. Além disso, a partir do que foi apresentado pelos professores, a maioria desses cursos não abordou aspectos relacionados à tendência que seria trabalhada no projeto de implementação, ou seja, a Modelagem Matemática. Do mesmo modo, não abordou aspectos das demais tendências em Educação Matemática, como explicitam algumas unidades de significado de professores como o P6: "[1:40] Durante o PDE não trabalhou nada específico da Modelagem"; "[1:36] A formação da parte pedagógica era para todos os professores, então não teve nada relacionado a essas metodologias para o ensino da Matemática”; e o P7: “[1:45] Durante o PDE não teve nada de Modelagem”.

$\mathrm{O}$ fato de os professores que ministram esses cursos, os direcionarem para uma Matemática mais "avançada" e não trabalharem com as tendências em Educação Matemática, pode suscitar alguns questionamentos, tais como: Qual é o conhecimento e prática desses professores acerca dessas tendências? Qual é o real alcance delas? Em que sentido e de diferentes modos isso poderia ser articulado no âmbito do PDE? Esse distanciamento entre aquilo que é abordado em cursos e os princípios teóricos e práticos das tendências, em especial de Modelagem Matemática na Educação Matemática, podem estar associados ao estilo de pensamento predominante e compartilhado entre os formadores de professores, que é diferente daquele que seria necessário ao desenvolvimento do trabalho com a tendência em foco (KLÜBER, 2012b). 
Nesse sentido, os dados apresentados nessa investigação nos mostraram, por um lado, que a presença dessas tendências na da sala de aula é apenas uma prescrição dos documentos oficiais, umas vez que parece não existir um trabalho efetivo com elas, mesmo quando se trata de uma política de formação continuada, como é o caso do PDE. Há apenas um discurso inicial sobre a adoção delas em sala de aula, sem que haja com os professores um trabalho que busque proporcionar um conhecimento mais aprofundado, tanto no que se refere à teoria como à prática pedagógica. Assim, sem um trabalho homogêneo, de acompanhamento dos professores, essas atividades de formação continuada, ao invés de colaborar para a implementação dessas tendências em sala de aula, tendem a fortalecer as práticas vigentes nas escolas.

Por outro lado, os questionamentos efetuados podem apontar para a ausência de pesquisadores e professores que atuam no Ensino Superior e que possuam uma prática corrente com essas tendências. Essa interpretação que é contextual pode indicar, também, que o alcance dessas tendências tem sido superficial, inclusive num ambiente de formação inicial de professores.

Desse modo, concordamos com o que é apresentado por Klüber (2012b, p. 73) quando menciona que:

Há uma urgência em tratar detidamente a formação de professores de matemática de maneira mais global, solicitando por uma mudança de postura de todos os professores em todos os níveis, tendo como principal agente no desencadeamento do processo os formadores de professores em nível superior.

Assim, investir na formação de professores significa se dedicar aos professores em formação inicial ou continuada de todos os níveis de ensino, para que as propostas educacionais não se restrinjam aos documentos, mas que possam ser exaustivamente discutidas e, se pertinentes, colocadas em prática. Buscando, desse modo, um processo de ensino e aprendizagem que proporcione o crescimento crítico, reflexivo e que favoreça a cidadania.

Nesse sentido, García (1999, p. 139, grifos do autor) afirma que

[...] O esforço para conseguir escolas mais participativas, onde os professores sejam inovadores e façam adaptações curriculares, onde as classes sejam locais de experimentação, colaboração e aprendizagem, onde os alunos aprendam e se formem como cidadãos críticos, passa necessariamente pela existência de professores capazes e comprometidos com os valores que tal representa.

Deve-se, no entanto, levar em consideração que uma mudança de atitude não é algo que acontece de uma hora para outra. Assim, ao se propor processos formativos tanto para professores em formação inicial como em formação continuada é necessário assumir que:

[...] mudar é algo difícil, pois envolverá reconhecer complicações no estilo de pensamento e ser capaz de superá-las, o que é iniciado com a inserção de alguns matizes, isto é, pequenas modificações no conhecimento construído coletivamente: ao nível pessoal isso requer reconhecer a própria ação, os 
seus fundamentos e trabalhar para modificá-la, consciente da imersão num contexto mais amplo (KLÜBER, 2012b, p. 66).

Além do que já apresentamos até aqui sobre os cursos desenvolvidos durante o PDE, voltamos ainda nossa atenção para o destaque feito pelos professores (P1, P2, P4, P6, P7 e P8) de que nenhum curso abordou a Modelagem Matemática. Desse modo, o contato desses professores com essa tendência em Educação Matemática se restringiu ao momento de elaboração e desenvolvimento do projeto de implementação, o que indica que não houve uma formação em Modelagem Matemática, houve apenas a utilização dessa tendência numa atividade eventual desenvolvida com os alunos. Essa falta de aprofundamento pode também ser resultado da influência (ou da falta) dos orientadores, uma vez que a maioria deles possui experiência na área da Matemática, sem convergências com a Educação Matemática ou com a formação de professores ${ }^{11}$.

Não estamos, com essa inferência, defendendo que a formação de professores em Modelagem se resume à participação em cursos eventuais e isolados desenvolvidos sob essa perspectiva. Contudo, resumir esse contato apenas ao desenvolvimento e implementação do projeto limita aprofundamentos, discussões, e a troca de experiência entre os pares, aspectos que podem contribuir para uma possível mudança de atitude na prática pedagógica. Nesse sentido, Garnica e Modesto (2005, p. 36) explicam que

[...] a busca de mudanças de prática, de posturas e de abordagens será tanto mais significativa quanto mais for desenvolvida coletivamente através de troca de ideias e experiências, reflexão, leitura e discussão, tanto nos momentos específicos de formação continuada, com os demais participantes, quanto no cotidiano escolar, com os demais membros da equipe.

Essa superficialidade com que a Modelagem Matemática foi abordada durante o PDE, se reflete na eventualidade com que ela foi abordada, em sala de aula, após a participação nesse programa. Em outras palavras, quando interpretamos a categoria "Sobre o projeto de implementação" que emergiu do discurso dos professores e que indicou, por exemplo, que os alunos lembram, até hoje, do que foi desenvolvido no projeto durante a participação no PDE - como explicitam as unidades do professor P2: "[1:58] Ao retornar para a sala de aula, trabalhou com os conteúdos "normais"; do professor P4: "[1:88] Os alunos até hoje lembram do projeto que foi desenvolvido"; e do professor P7: "[1:11] Até hoje os alunos lembram do que foi desenvolvido no projeto", "[1:63] Por mais que não haja uma sequência, o trabalho ficou marcado para os alunos" - revela-se que essa prática em sala de aula não se tornou recorrente, foi algo ilustrativo, indicando que o PDE não auxiliou, ao menos fortemente, à incorporação da prática de Modelagem Matemática pelo professor.

Essa afirmação converge para o que é apresentado na categoria "Sobre a prática pedagógica", da qual se revela que a prática, dos professores que tiveram as suas aulas observadas,

\footnotetext{
${ }^{11}$ Essa afirmação é efetuada tendo em vista os currículos dos professores que orientaram os trabalhos dos professores participantes deste estudo.
} 
está voltada para um processo de ensino e aprendizagem centrados na exposição do conteúdo e na resolução de exercícios, como podemos observar, por exemplo, em algumas unidades de significado destacadas dos diários de observação construídos a partir das observações das aulas dos professores. Nesse sentido, do professor P1, observamos, dentre outros aspectos que: "[1:1] O professor efetuou uma revisão do conteúdo por meio de uma exposição oral'; nas aulas do professor P6: "[1:66] A revisão do conteúdo seguia um padrão: o professor apresentava o nome do conteúdo e passava alguns exemplos no quadro"; "[1:71] Na revisão, as perguntas para os alunos eram pontuais e se restringiam aos exemplos"; "[1:78] As resolucõos eram efetuadas pelo professor e os alunos não tinham tempo de pensar na resolução"; e nas aulas do professor P8: "[1:54] As aulas ficavam voltadas à resolução dos exercicios da prova"; "[1:49] Os exercícios propostos se resumiam a aplicação de técnicas".

Além disso, durante as aulas observadas, os professores, na sua grande maioria, demonstraram não valorizar o trabalho em grupo e nem o diálogo entre os alunos - professor P1: "[1:17] Na maioria das vezes os alunos trabalhavam individualmente"; professor P6: "[1:75] Os alunos trabalhavam individualmente e o professor os auxiliava quando solicitado"; e, professor P8: "[1:44] Para essa revisão os alunos trabalharam individualmente e o professor ajudava os alunos" - o que corrobora com o que afirmamos anteriormente, isto é, que os professores não tiveram uma formação em Modelagem e nem foram afetados por características que são próprias de uma atividade desenvolvida sob essa perspectiva. Essa interpretação reafirma também o caráter episódico dos projetos desenvolvidos, pois, a partir daquilo que se mostrou da interpretação dos dados, a implementação do projeto significou, em última instância, apenas a realização de uma atividade obrigatória do PDE.

Frente a tudo isso, podemos dizer, na articulação das categorias "Sobre o discurso acerca da prática pedagógica" e "Sobre o discurso relativo à prática docente e a Modelagem Matemática”, presentes na interpretação dos dados de três professores, que o PDE não incitou mudanças relevantes na atuação do professor em sala de aula no tocante à Modelagem, dado ainda mais fortalecido pela observação das aulas de um deles, o qual mantém a sua prática voltada aos aspectos técnicos, de um ensino mais usual, mesmo argumentando, que quando o professor trabalha somente com a exposição do conteúdo, acaba se "iludindo", acreditando que os alunos aprenderam, como observamos na unidade do professor P6: "[1:15] Quando o professor trabalha só no quadro, expondo fórmulas, acaba se iludindo pensando que o aluno aprendeu”.

Há, nesse sentido, um distanciamento entre a prática pedagógica e o discurso do professor, ou seja, por mais que ele afirme que a utilização exclusiva de características do ensino tradicional não proporcione a aprendizagem significativa, em sua prática há presença dessas características. Nesse contexto, podemos afirmar, dentre outros aspectos, que os processos formativos que participou não contribuíram para que ele pudesse alterar a sua postura em sala de aula, em termos de inovações pedagógicas. Outro professor, que comentou sobre a prática docente, disse que gosta de trabalhar com a metodologia de projetos e que, mesmo antes da participação no PDE já a utilizava em sala de aula. No entanto, não podemos inferir se ele tem essa prática ou não, pois não observamos suas aulas.

No que se refere ao terceiro professor (P3) que discorreu sobre aspectos relacionados à prática pedagógica, destacamos que ele foi o único, dos quais observamos as aulas, que trabalhou de um modo diferenciado, buscando apresentar a Matemática relacionada ao dia a dia do aluno - o que ratifica seu discurso de que em determinados momentos trabalha com temas em sala de aula. Essa postura diferenciada pode estar relacionada com o fato de ele ter tido 
contato, durante o PDE, com atividades de Modelagem: "[1:13] O curso de Modelagem teve a maior carga horária"; "[1:14] A parte de Modelagem foi interessante porque foi trabalhado na prática". Para esse docente, o interesse pessoal, a formação oferecida e a orientação qualificada, no sentido de ser um docente que pesquisa sobre Modelagem, parece ter influenciado na adoção da tendência.

Como mencionamos, parece que o PDE não gerou, de maneira generalizada, impacto na prática dos professores. Essa afirmação, além do que já apresentamos, corrobora com o que é explicitado nas categorias "Sobre o pós PDE", e "Sobre a Modelagem antes e depois do PDE", quando alguns professores relataram não ter voltado a desenvolver o projeto, como por exemplo, o professor P1: "[1:45] O professor não voltou a utilizar a Modelagem e nem o projeto em sala de aula"; o professor P4: "[1:47] Ao assumir 40 horas o professor não ach a possivel desenvolver um projeto, como o que foi desenvolvido no PDE"; e, o professor P5: "[1:7] Ao retornar do PDE o professor assumiu a direção do colégio"; "[1:46]: Ao retornar do PDE, ele tinha aulas em 4 colégios e não conseguia preparar algo diferente". Não emergiram dos discursos argumentos de que utilizam de modo efetivo a Modelagem Matemática em sala de aula. O seu uso, quando aparece, se mostra algo eventual, no qual o professor não demonstra segurança, como destacado pelo professor P2: "[1:60] Devido a dificuldade da turma, o professor ficou inseguro para desenvolver o seu projeto que fazia o uso da Modelagem".

Nesse mesmo sentido, três professores, na categoria "Sobre o projeto de implementação" também discorrem sobre o uso da Modelagem e do projeto após a participação no PDE. Dois deles relataram que não voltaram a utilizar o projeto, o professor P8: "[1:21] Não aplicon mais o projeto porque não estava trabalhando com formação de docentes". Apenas um, disse que tem o interesse de continuar o trabalho com Modelagem, mas que falta prática: professor P3: "[1:61] Mas, o professor diz que ainda falta prática de Modelagem".

Assim, como já mencionamos, revela-se superficialidade da formação em Modelagem Matemática no PDE, inclusive com os professores que trabalharam com essa tendência nos projetos de implementação. Superficialidade que se mostra nas práticas observadas e também nos discursos dos professores.

Dizemos que há também uma superficialidade no discurso sobre a Modelagem Matemática tendo em vista o que foi apresentado por cinco professores, os quais convergiram para as categorias: "Sobre a concepção e adoção da Modelagem", "Sobre a Modelagem Matemática", "Sobre o uso da Modelagem Matemática antes do PDE e considerações sobre essa tendência" e "Sobre o discurso relativo a prática docente e a Modelagem Matemática". Em outras palavras, os professores, em sua maioria, ao mencionarem essa tendência nos seus relatos não enfatizaram aspectos particulares, falaram de aspectos gerais, amplamente disseminados na comunidade de Modelagem Matemática, tais como: a motivação e envolvimento dos alunos; a possibilidade de trabalhar com temas do dia a dia do aluno; o fato de a Modelagem não se preocupar apenas com o conteúdo matemático. Como mostra, por exemplo, o discurso do professor P2: "[1:81] Com o uso da Modelagem o professor busca o aluno, traz a Matemática para o seu dia a dia"; do professor P6: "[1:18] Com o trabalho com Modelagem os alunos se sentem motivados"; e, do professor P7 "[1:71] Quando trabalha com Modelagem, o professor aborda diferentes conteúdos de uma única vež".

No entanto, há também aqueles discursos que buscam resumir a Modelagem à uma única perspectiva, como é o caso do professor P2 que afirma que para trabalhar com ela em sala de aula, basta aplicá-la ao conteúdo: "[1:44] Para trabalhar com essa tendência em sala de aula é só aplicar a Modelagem dentro do conteúdo programado". Nesse mesmo sentido, há aqueles professores que citam como principal referência na área da Modelagem o autor Ubiratan D’Ambrosio e que 
afirmam que o trabalho com essa tendência exige um período mais longo, dificultando a sua implementação em sala de aula, tendo em vista o currículo escolar. A explicitação de D'Ambrosio como principal referência da área da Modelagem pode indicar, conforme mencionamos em Tambarussi (2015) a falta de rotina de estudos do professor para compreender melhor essa tendência, uma vez que cita apenas um autor. Compreendemos, por um lado, a importância do autor para a área, mas, por outro, entendemos que existem discussões e referenciais mais atualizados que ajudam a compreender os distintos aspectos da Modelagem Matemática na perspectiva da Educação Matemática.

Todas essas afirmações podem indicar o pouco aprofundamento, de cunho teórico, que foi dado à Modelagem. Não estamos com isso afirmando que a única preocupação do PDE deve ser a Modelagem e nem que os cursos ofertados seriam suficientes para que os professores tivessem uma formação nessa tendência. No entanto, essa superficialidade no discurso e a não adoção dessa tendência após o término do PDE, mostra que mesmo aqueles que trabalharam com essa tendência durante o período a ele dedicado, não foram significativamente influenciados pela "formação" que tiveram. Apresentam, em muitos casos, um discurso de apologia ao uso da Modelagem, mas não a utilizam em sala de aula. Essa afirmação corrobora com o discurso apresentado por Barbosa (2001b, p. 6) quando menciona:

É possível afirmar que os programas de formação em Modelagem não têm tido dificuldades para convencer os professores sobre a plausibilidade de suas propostas. Pelo menos no discurso, a Modelagem e atividades de semelhante natureza são defendidas pelos docentes. Entretanto, isto não significa que os professores mudaram suas concepções acerca de seu trabalho.

A esses argumentos, podemos acrescentar as categorias "Sobre a Modelagem Matemática antes do PDE", "Sobre o uso da Modelagem Matemática antes do PDE e considerações sobre essa tendência" e "Sobre a Modelagem: antes e depois do PDE", e aquilo que foi apresentado nas categorias relacionadas à prática pedagógica mencionado anteriormente, no qual retrata que por mais que alguns professores já conhecessem a Modelagem e defendessem a sua utilização (no nível do discurso), a prática em sala de aula continua presa a aspectos do ensino tradicional.

A afirmação efetuada por Barbosa (2001b) de que os programas de formação não têm dificuldades em convencer os professores sobre as potencialidades da Modelagem, embora não tenham conseguido transformar o trabalho em sala de aula, também se mostra presente quando alguns professores afirmam que já conheciam a Modelagem devido a participação em especializações e cursos que abordaram essa tendência, como mostra, respectivamente o discurso dos professores P2 e P5: "[1:6] O primeiro contato com a Modelagem foi em um curso"; "[1:67] O professor desenvolven 'algumas partes da Modelagem”; "[1:16] Fez uma especialização na área de Modelagem”- e, mesmo assim, não utilizam a tendência em sala de aula, como apresentamos anteriormente. Apenas um professor (P6) comentou que não tinha conhecimento sobre o que era a Modelagem - "[1:11] Nunca tinha trabalhado com Modelagem em sala de aula" - e o discurso de outro professor revelou a ausência total dessa tendência, tanto no que se refere ao momento anterior quanto no momento da participação e após o PDE.

Assim, ao interrogar o fenômeno Formação de Professores em Modelagem a partir de professores egressos do PDE reforça-se o argumento de que as atividades de formação continuada não têm 
causado impacto no âmbito da sala de aula, pois mesmo alguns professores já conhecendo a Modelagem, o seu uso parece ainda ser algo eventual, isso se torna mais evidente quando olhamos para as práticas que observamos dos professores após a participação no PDE e, também para o discurso daqueles que não tiveram suas aulas observadas. Em outras palavras, o discurso de apologia e o desenvolvimento de atividades isoladas de Modelagem não têm contribuído para que os professores utilizem essa tendência em sala de aula, isto é, a incorporem na sua prática docente.

Desse modo, a investigação aponta para a necessidade de conceber formações, de modo particular formações continuadas em Modelagem, que possam transcender esse discurso de apologia, ou seja, que as mudanças cheguem também na prática do professor em sala de aula. Essa é uma lacuna que se dirige a toda a comunidade de Modelagem Matemática na Educação Matemática. Para isso, é necessário um trabalho efetivo e permanente com os professores, no qual seja possível a constituição, por exemplo, de um coletivo de Modelagem, em que os professores possam ser, entre outras coisas, induzidos, acompanhados e amparados em suas práticas e que tenham um ambiente para discussões e aprofundamentos.

Nesse contexto, apresentamos a afirmação de Escudero (1992 apud GARCÍA, 1999, p. 139), direcionada à formação continuada de professores:

[...] a formação e a mudança devem ser pensadas em conjunto... hoje é pouco defensável uma perspectiva sobre a mudança para o aperfeiçoamento da educação que não seja, em si mesma, capacitadora, geradora de sonho e compromisso, estimuladora de novas aprendizagens e, em suma, formativa para os agentes que têm de desenvolver as reformas na prática. Simultaneamente, a formação bem entendida deve estar preferencialmente orientada para a mudança, ativar reaprendizagens nos indivíduos e na sua prática docente, que tem de ser, pelo seu lado, facilitadora de processos de ensino e aprendizagem dos alunos.

Em acréscimo ao que explicitamos, trazemos o argumento de Ponte (1998) que fala do cuidado que devemos ter com as propostas de formação de professores de Matemática, principalmente em se tratando de carga horária e modelos de formação de professores, esclarecendo que

\footnotetext{
Há, por vezes, a tentação de estabelecer objectivos demasiados ambiciosos para a formação. Pretende-se, com uma pequena acção de um mês (ou de 50 horas), proporcionar um vasto leque de conhecimentos e competências ao professor e mudar a sua visão de currículo, do ensino da Matemática, e até do seu papel profissional. [...] Outras vezes definem-se objectivos que parecem ser realistas e interessantes mas não correspondem, de facto, aos problemas reais que os professores sentem na sua prática (PONTE, 1998, p. 10).
}

Ainda que o PDE seja uma formação que busque se diferenciar das convencionais, pois propõe, dentre outros aspectos, um período mais longo destinado à formação e discussões mais próximas daquilo que é vivenciado pelos professores em sala de aula, ela é subsidiária de um 
modelo de formação que reafirma a dicotomia entre teoria e prática, a partir dos aspectos que apresentamos. Dessa perspectiva, podemos afirmar que os aspectos aqui explicitados transcendem o lócus específico do programa, porque ele é, de alguma maneira, uma expressão de um cultura de formação amplamente disseminada na tradição brasileira. Sob esse entendimento, descrevemos na sequência uma reflexão geral sobre o fenômeno focado, buscando cotejar contribuições para área de Modelagem Matemática na Educação Matemática.

\section{Síntese e reflexões}

Aquilo que discorremos sobre a formação de professores em Modelagem Matemática segundo a experiência dos professores participantes do PDE, transcende os aspectos locais. A formação que foi oportunizada se assemelha a tantas outras já ofertadas em diferentes regiões do país e sob uma cultura de formação que em geral apenas informa, como podemos observar em Tambarussi e Klüber (2014a). No tocante à adoção da Modelagem isso se mostra prejudicial à formação dos professores, uma vez que não contempla aspectos inovadores e mesmo epistemológicos, como uma dimensão investigativa e temática, que garantiriam um conhecimento mais pleno sobre ela.

Em certo sentido, podemos afirmar que um tempo longo de formação não resulta na qualidade dela. Em Modelagem, por suas características interdisciplinares, investigativa e temática, sem dúvida uma das dimensões a ser contemplada é a oferta de formações mais extensas, contudo, é preciso associá-la à dimensão da intensidade e engajamento específico. Em outras palavras, de nada adianta permanecer por um longo tempo em formação, sem aquisição dos conhecimentos e saberes necessários ao desenvolvimento da prática pretendida.

Além disso, podemos afirmar que uma formação em Modelagem Matemática, ainda que contemple em seu itinerário um momento de atuação e ação, não garante à continuidade do trabalho. Longe de apresentarmos uma solução para uma situação tão complexa, somos incitados a manter um posicionamento crítico em relação às diversas variáveis envolvidas. Dentre elas, podemos dizer que a prática carece de acompanhamento e reflexão de pessoas que são iniciadas ou com ampla disposição à mudança da sua própria prática. Alguns caminhos começam a emergir na comunidade de Modelagem, como a constituição de grupos colaborativos ${ }^{12}$, ainda que já existam, desde o final da década de 1990, trabalhos que se dediquem ao estudo de grupos colaborativos em Educação Matemática no Brasil, como se pode ver em Passos et al. (2006).

Diante disso, aquilo que ora apresentamos nesse artigo, corrobora com as discussões sobre formação de professores em Modelagem, porque supera argumentos do senso comum pedagógico e da área de formação de professores em geral. A longa duração da formação, o retorno à universidade e a prática como componente da formação não são garantias para adoção dessa tendência. Assim, há que se questionar: Como organizar e gerir o tempo? O que mais é

\footnotetext{
${ }^{12}$ Trabalhos sob essa perspectiva vêm sendo desenvolvidos pelo Grupo Colaborativo em Modelagem, coordenado pela profa. dra. Andréia Maria Pereira de Oliveira. Currículo Lattes disponível em: <http:// buscatextual.cnpq.br/buscatextual/visualizacv.do?id=K4771995D1>. Acesso em: 16 out. 2017.
} 
necessário além de um tempo longo? Que teorias podem auxiliar a compreender essa dicotomia: tempo/aquisição de conhecimentos ou saberes? A comunidade pode, a partir de um consenso coletivo, indicar caminhos a serem percorridos? De que modo as práticas devem aparecer no contexto da formação em Modelagem? Qual é o efetivo papel da Universidade na socialização, acolhimento e acompanhamento dos professores?

Encerramos esse texto na expectativa de fomentar mais pesquisas sobre os pontos que elencamos e, ao mesmo tempo, socializar a compreensão que tivemos sobre a formação de professores em Modelagem. Desse modo, há muito a ser investigado com vistas a aprofundar ou refutar práticas vigentes, pois, como explicitamos, há conceitos e crenças que marcam a formação de professores e que precisam ser interrogados criticamente.

\section{Agradecimentos}

Este trabalho foi financiado pela Coordenação de Aperfeiçoamento de Pessoal de Nível Superior (Capes) e pela Fundação Araucária, além de estar vinculado ao projeto de pesquisa "Modelagem matemática na educação matemática: metapesquisa e formação de professores", aprovado no edital universal da Capes, sob o processo no 406721/2013-0.

\section{Referências}

BARBOSA, J. C. Modelagem matemática e os professores: a questão da formação. Bolema, Rio Claro, n. 15, p. 5-23, 2001b. Disponível em: <http://www.ufrgs.br/espmat/disciplinas/ funcoes_modelagem/modulo_VI/pdf/Mod-Mat-formacao-professores.pdf $>$. Acesso em: 16 out. 2017.

BARBOSA, J. C. Modelagem na educação matemática: contribuições para o debate teórico. In: REUNIÃO ANUAL DA ANPED, 24., 2001a. Caxambu. Anais... Caxambu: AMPED, 2001a. p. 1-30.

BICUDO, M. A. V. Fenomenologia: confrontos e avanços: São Paulo: Cortez, 2000.

. Meta-análise: seu significado para a pesquisa qualitativa. Revemat, Florianópolis, v.

9, n. 1, p. 7-20, 2014. Disponível em: <https://doi.org/10.5007/1981-1322.2014v9nespp7>. Acesso em: 17 out. 2017.

. Pesquisa qualitativa e pesquisa qualitativa segundo a abordagem fenomenológica. In: BORBA, M. C. et al. Pesquisa qualitativa em educação matemática. Belo Horizonte: Autêntica, 2006. p. 99-112.

BICUDO, M. A. V.; PAULO, R. M. Um exercício filosófico sobre a pesquisa em educação matemática no Brasil. Bolema, Rio Claro, v. 25, n. 41, p. 251-298, dez. 2011. Disponível em: <http://www.redalyc.org/pdf/2912/291223514012.pdf>. Acesso em: 17 out. 2017. 
BRASIL. Lei $\mathbf{n}^{\circ}$ 9394, de 20 de dezembro de 1996. Estabelece as diretrizes e bases da educação nacional. Disponível em: < http://www.planalto.gov.br/ccivil_03/leis/L9394. htm>. Acesso em: 20 jan. 2015.

CARNEIRO, R. F. A formação de professores dos anos iniciais em um curso de pedagogia: contribuições das disciplinas de matemática. In: SEMINÁRIO INTERNACIONAL DE PESQUISA EM EDUCAÇÃO MATEMÁTICA, 6., 2015, Pirenópolis. Anais... Pirenópolis: SBEM, 2015. p. 1-11.

EMENTA GT07. [S.1.]: Sociedade Brasileira de Educação Matemática, 2012. Disponível em: $<$ http://www.sbembrasil.org.br/sbembrasil/index.php/81-grupo-de-trabalho/566-ementagt07>. Acesso em: 29 ago. 2016.

FANIZZI, S.; SANTOS, V. M. Políticas públicas de formação continuada de professores dos anos iniciais em matemática: uma experiência da Secretaria Municipal de Educação de São Paulo. In: SEMINÁRIO INTERNACIONAL DE PESQUISA EM EDUCAÇÃO MATEMÁTICA, 6., 2015, Pirenópolis. Anais... Pirenópolis: SBEM, 2015. p. 1-11.

GARCÍA, C. M. Formação de professores: para uma mudança educativa. Portugal: Porto Editora, 1999.

GARNICA, A. V. M. Educação, matemática, paradigmas, prova rigorosa e formação do professor. In: BICUDO, M. A. V.; CAPPELLETTI, I. F. (Org.). Fenomenologia: uma visão abrangente da educação. São Paulo: Olho D’água, 1999. p. 105-154.

GARNICA, A. V. M.; MODESTO, M. A. Ouvindo professores de matemática: um estudo sobre formação (continuada). Guairaca, Guarapuava, v. 19, p. 31-55, 2005.

GIL, A. C. Como elaborar projetos de pesquisa. São Paulo: Atlas, 2010.

GIUSTI, N. M. R.; JUSTO, J. C. R. Processos colaborativos e cooperativos interseccionados na formação em serviço de professores dos anos iniciais. In: SEMINÁRIO INTERNACIONAL DE PESQUISA EM EDUCAÇÃO MATEMÁTICA, 6., 2015, Pirenópolis. Anais... Pirenópolis: SBEM, 2015. p. 1-11.

HERMANN, N. Hermenêutica e educação. Rio de Janeiro: DP\&A, 2002.

HESSEN, J. Teoria do conhecimento. Coimbra: Arménio Amado, 1980.

KLÜBER, T. E. (Des) Encontros entre a modelagem matemática na educação matemática e a formação de professores de matemática. Alexandria: revista de educação em ciência e tecnologia, Florianópolis, v. 5, n. 1, p. 63-84, 2012b. Disponível em: < https://periodicos.ufsc. br/index.php/alexandria/article/view/37697/28868>. Acesso em: 17 out. 2017.

Uma metacompreensão da modelagem matemática na educação

matemática. 2012a. 396 f. Tese (Doutorado em Educação Científica e Tecnológica) Universidade Federal de Santa Catarina. Florianópolis, 2012a.

PARANÁ. Secretaria de Estado da Educação. Documento síntese. Curitiba: SEED, 2013. Disponível em: < http://www.gestaoescolar.diaadia.pr.gov.br/arquivos/File/pde_ roteiros/2013/documento_sintese_2014_incorporando_avaliacao.pdf $>$. Acesso em: 28 set. 2017. 
PASSOS, C. L. B. et al. Desenvolvimento profissional do professor que ensina matemática: uma meta-análise dos estudos brasileiros. Quadrante, Lisboa, v. 15, n. 1-2, p. 193-219, 2006. Disponível em: <http://www.apm.pt/files/_09_lq_47fe12e32858f.pdf>. Acesso em: 17 out. 2017.

PASSOS, C. L. B.; SOUZA, A. P. G. Formação inicial/continuada de professores dos anos iniciais: tecnologias informáticas e Mmatemática. In: SEMINÁRIO INTERNACIONAL DE PESQUISA EM EDUCAÇÃO MATEMÁTICA, 6., 2015, Pirenópolis. Anais... Pirenópolis: SBEM, 2015. p. 1-11.

PONTE, J. P. Da formação ao desenvolvimento profissional: conferência plenária. In: ENCONTRO NACIONAL DE PROFESSORES DE MATEMÁTICA, 1998, Guimarães. Actas... Lisboa: APM, 1998. p. 27-44.

SANTANA, F. C. M.; BARBOSA, J. C. P Trabalho colaborativo com professores de matemática: uma análise dos conflitos entre/nos textos enunciados pelos participantes. In: SEMINÁRIO INTERNACIONAL DE PESQUISA EM EDUCAÇÃO MATEMÁTICA, 6., 2015, Pirenópolis. Anais... Pirenópolis: SBEM, 2015. p. 1-13.

STEIN, E. Aproximações sobre hermenêutica. Porto Alegre: EDIPUCRS, 2004.

TAMBARUSSI, C. M. A formação de professores em modelagem matemática: considerações a partir de professores egressos do Programa de Desenvolvimento Educacional do Paraná - PDE. 2015. 179 f. Dissertação (Mestrado em Educação) Universidade Estadual do Oeste do Paraná, Cascavel, 2015.

TAMBARUSSI, C. M.; KLÜBER, T. E. A pesquisa em modelagem matemática: sobre as atividades de formação continuada em teses e dissertações. Revemat, Florianópolis, v. 9, p. 38-56, 2014a. Disponível em: < https://doi.org/10.5007/1981-1322.2014v9nespp38>. Acesso em: 17 out. 2017.

Focos da pesquisa stricto sensu em modelagem matemática na educação matemática brasileira: considerações e reflexões. Educação Matemática Pesquisa, São Paulo, v. 16, n. 1, p. 209-225, 2014b. Disponível em: < https://revistas.pucsp.br/index.php/emp/article/ view/16695/pdf>. Acesso em: 17 out. 2017.

Artigo recebido em 11/09/2016. Aceito em 12/03/2017.

Endereço para contato: Avenida 22A, CEP 13506-705, Rio Claro, SP, Brasil. 